
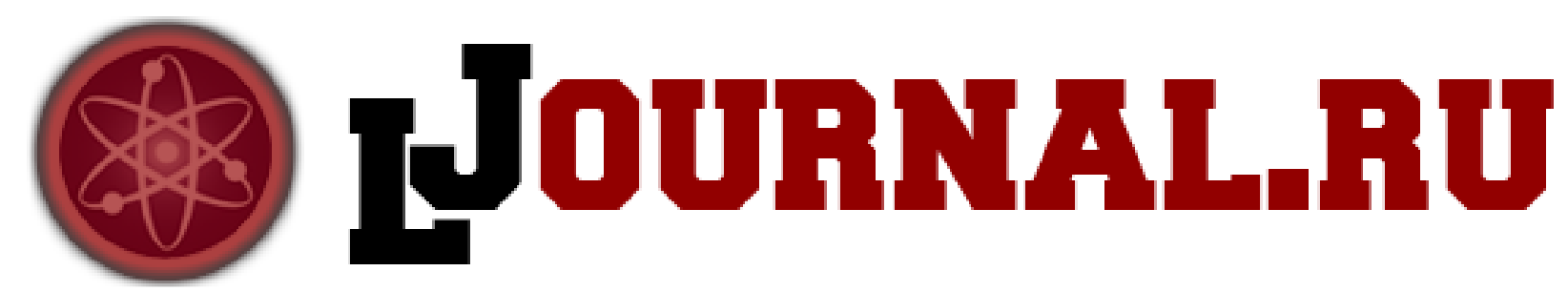

\author{
Варлашина С.Ю., Наземнова Н.В. \\ ГАПОУ ПО «Пензенский многопрофильныий колледж» \\ Пенза, Россия
}

doi: 10.18411/1j2016-2-04

\title{
Аналогия как фактор формирования поисковой мотивации учащихся при обучении математике
}

Согласно учению о детерминации активности человека внутренняя активность субъекта деятельности определяется внешней активностью и, наоборот, внешние проявления зависят от внутренних. С позиции А.В. Петровского, внутреннюю активность составляют в первую очередь мотивы и потребности как источник активности. Поэтому успех процесса и результата обучения математике школьников напрямую будут зависеть от работы, направленной на упрочнение и развитие мотивационной сферы учащихся [4].

Актуализация мотивационных факторов в процессе обучения математике может проходить либо напрямую - путем непосредственного внешнего воздействия на тот или иной мотивационно-потребностный компонент в структуре личности (ситуативная мотивация), либо на основе опосредованного влияния на организацию самой мотивационной сферы через овладение способами учебной деятельности, механизмами обратной связи, различными эвристическими приемами, подкрепляемое позитивным опытом их применения. Во втором случае ученик получает возможность произвольной и целенаправленной инициации собственной деятельности без прямого стимулирования из вне (надситуативная мотивация) [5].

Определяя основные пути обеспечения эффективного функционирования учебной мотивации школьников при формировании действий по распознаванию 
образа, целесообразно исходить из двух направлений.

Первое направление состоит в создании специальных условий, способствующих актуализации мотивационных факторов, таких как условия посильной трудности предлагаемых заданий, актуализация субъектной позиции ученика, обеспечение самодиагностики, эмоциональный настрой класса и других.

Другое направление обеспечения поисковой мотивации учащихся заключается в относительно самостоятельном преодолении ими трудностей, возникших в ходе обучения приемам распознавания геометрических образов. Преодолевая это несоответствие (противоречие, барьер), ученик испытывает «волнующее чувство маленького открытия», которое способствует мотивации его последующей поисковой деятельности.

C методических позиций формирование уверенности в успешной предстоящей деятельности исследовал Д. Пойа, который выделил ряд факторов, этому способствующих: подтверждение следствий; аналогия с известным фактом; правдоподобие промежуточных результатов; индуктивная проверка и т.д.

К основным методам формирования действия по распознаванию образа относятся: аналогия, сравнение, обобщение, конкретизация. Аналогия как метод формирования действия по распознаванию образа характеризуется тем, что из сходства двух объектов в нескольких признаках и при наличии у одного из них дополнительного признака делается вывод о наличии такого же признака у другого объекта. Вывод по аналогии является предположительным и подлежит последующему обоснованию. Аналогию как метод обучения можно использовать на этапе введения нового понятия и прогнозирования его свойств, а также способов при обучении решению задач, доказательству теорем.

В процессе обучения математике учителю следует приобщать учащихся к самостоятельному проведению умозаключений по аналогии. Применение аналогии является одним из эффективных приемов, способствующих 
формированию действия по распознаванию образа у учащихся. Этот метод приобщает детей к такому виду деятельности, который называют исследовательским. Кроме того, широкое применение аналогии дает возможность более легкого и прочного усвоения школьниками учебного материала, так как часто обеспечивает мысленный перенос определенной системы знаний и умений от неизвестного объекта к известному.

Говоря о применении аналогии в обучении школьников математическим методам распознавания геометрических образов, можно выделить аналогию: 1) между свойствами геометрической и арифметической прогрессий; 2) в изучении свойств фигур на плоскости и свойств фигур в пространстве, например в изучении треугольника и тетраэдра, параллелограмма и параллелепипеда, прямоугольника и прямоугольного параллелепипеда и т.п. Следует отметить, что такое представление о роли аналогии в обучении математике сильно ограничивает ее возможности, особенно применение аналогии в контексте обучения учащихся решению задач. Так, решение одной задачи может быть использовано в решении другой задачи, аналогичной первой, т.е. имеющей с первой сходные условия или заключения. Для этого каждый шаг решения одной задачи «переносится» на решение другой. При этом предвосхищение успешного результата, как и его последующее достижение, предполагает осознание учеником всей структуры деятельности по решению задачи, мотивированности его шагов, звеньев, промежуточных задач, ближайших и отдаленных последствий получения их результатов - то, что принято называть внутренним планом деятельности. Возможность такого осознания определяется индивидуальным «когнитивным фондом идентификации», включающим в себя запас знаний о существенных опознавательных признаках задачи; программы поисковых стратегий и приемов творческой деятельности, а также способность к их мобильной и гибкой актуализации, которая является одним из ведущих показателей интеллектуального развития человека [5].

Школьные учебники математики, алгебры и геометрии имеют широкие 
возможности для формирования приема аналогии в изучении математики.

Рассмотрим несколько задач, позволяющих описать общую характеристику приема аналогии и выделить действия, его составляющие.

В качестве примеров приведем формулировки двух задач на доказательство:

1. Докажите, что медианы треугольника пересекаются в одной точке и в точке их пересечения делятся в отношении 2:1, считая от вершины.

2. Докажите, что медианы тетраэдра пересекаются в одной точке и в точке их пересечения делятся в отношении $3: 1$, считая от вершины.

Рассуждения в доказательствах приведенных задач 1 и 2 опираются на аналогию между треугольником и тетраэдром. В ходе выполнения подобных заданий процесс выделения конкретного объекта из множества; упор на взаимосвязи, определяющие последовательную реализацию рассуждений, запускает у учащегося механизм предвосхищения результата, что задает ориентир для последующей актуализации и развития его учебной мотивации.

Обычно, когда говорят об аналогии в различной методической литературе, ее связывают с фигурами на плоскости и пространстве, между тем аналогия широко может применяться не только при решении задач на доказательство, вычисление или построение, но и при изучении свойств геометрических фигур[3].

Но чрезмерное увлечение аналогией при обучении приемам распознавания геометрических образов может отрицательно сказаться на совершенствование мотивационной сферы учащихся, так как оказывает негативное влияние на реализацию поисковых процессов. Здесь необходимо отметить, что вывод по аналогии может быть истинным и ложным.

Пример. Площадь любого треугольника выражается формулой Герона

$$
S=\sqrt{p *(p-a) *(p-b) *(p-c)} .
$$

Изыскивая формулы для вычисления площади четырехугольников, мы 
можем задаться вопросом: верна ли аналогичная формула для четырехугольника?

Исследование этого вопроса показывает, что для четырехугольников, вписанных в окружность (и только для них!), справедлива следующая формула для вычисления площади:

$$
S=\sqrt{(p-a) *(p-b) *(p-c) *(p-d)} .
$$

Оказалось, что здесь полная аналогия не имеет места.

Отправляясь далее от обнаруженной аналогии в формулах, можно выяснить причину этой аналогии: существует связь между треугольником (многоугольником, который всегда можно вписать в окружность) и четырехугольником (не всяким, а только таким, который можно вписать в окружность).

Итак, существенным признаком, объединяющим треугольник и четырехугольник (в смысле общности формулы Герона), является возможность вписать их в окружность.

В школьном курсе геометрии абсолютное большинство стереометрических фактов излагается без установления внутрипредметных связей с аналогичными планиметрическими фактами. Это есть следствие линейного построения курса геометрии. Определяя основные пути обеспечения эффективного формирования мотивационной сферы учащихся, учителю целесообразно произвести трансформацию линейного построения содержания школьного курса геометрии в линейно-концентрическое. Это даст возможность проводить глубокие сравнения, широкое обобщение, выдвигать гипотезы и предположения, переносить знания, умения и навыки в новую ситуацию, переосмысливать с новых, более общих позиций, уже ранее изученный материал.

В избегании негативного влияния аналогии на развитие учебной мотивации школьников при обучении приемам распознавания геометрических образов необходимо требовать от них постоянно обосновывать выполняемые 
математические операции с ссылками на определение, теоремы, формулы, чтобы добиваться сознательного и прочного усвоения материала. При решении упражнений необходимо руководствоваться принципом «Сначала правило, потом действие. Без правила нет действия!». В процессе преподавания надо не только подчеркивать истинные аналогии, но и отличать ложные, разрушать их с целью предупреждения возможных ошибок.

\section{Литература:}

1. Атанасян Л. С. Геометрия: Учебник для 10-11 классов ср. школы.- М.: Просвещение, 2003.

2. Дорофеев С. Н. Индивидуальная траектория обучения как средствореализации деятельностного похода/Известия высших учебных заведений. Поволжский регион //Педагогические науки.-№1, 2013.- С.5256

3. Дорофеев С. Н. Личностно ориентированный подход как основа построения индивидуальных траекторий обучения математике/«Мир науки, культуры и образования»//Горно-Алтайск.-№2(30)2013.- С.48-50

4. Петровский А. В. Мотивация как проявление потребностей личности/ А.В. Петровский // Общая психология. $\square$ М., 1976. С. $110 \square 135$.

5. Родионов М. А. Мотивация учения математике и пути ее формирования: Монография / М. А. Родионов $\square$ Саранск: Издво МГПИ им. М. Е. Евсевьева, 2001. $\square$ С. 108112. 